\title{
The multiple faces of journal peer review
}

\author{
Sven Thatje
}

Published online: 3 February 2010

(C) Springer-Verlag 2010

There is probably no case that has shaped the academic world as much as the institution of the peer-review system. Peer review of scholarly work has existed for centuries (Kronick 1990, and references therein); however, its use across all fields of science and academia is the result of seeking consensus in quality standards of published work, a process that has mainly developed throughout the second half of the 20th century. Today, even graduate students have a perception of the use and impact of peer review in science, and its importance on one's personal career perspectives. Originally aiming to improve the quality of publishing in academic journals, peer review has become part of many aspects of the academic process, ranging from the assessment of research proposals and reports, to performance assessment and promotion processes of the peers themselves.

So, is this a bad thing? There is no doubt that peer review has contributed to increased publication standards and the advancement of science through academic discussion (Kinne 1988; 1999). On the other hand, the peerreview system has led to the evolution of publication-based assessment criteria, which dominate any evaluation of an academic's career. Almost everyone working in academia today is aware of the most important measures of publication success, such as journal impact factor, h-factor, and several additional indices that can be discussed (Bornmann and Daniel 2010; Thompson et al. 2007).

Should we allow this system of categorisation to dictate research and its publication? How much does an individual

\section{S. Thatje $(\bowtie)$}

National Oceanography Centre, Southampton,

School of Ocean and Earth Science, University of Southampton,

European Way,

Southampton SO14 3ZH, UK

e-mail: svth@noc.soton.ac.uk publication record indicate the quality of science and the academic potential of a scientist? It can probably be agreed that publishing in a high-impact journal does not necessarily reflect what is 'good' or 'bad' science; however, it does indicate the size of the audience that could be attracted to read - and cite - such a paper. Whether sticking to research with mainstream interest is necessarily the most innovative and significant route remains subject to discussion, and in many cases only time can tell. However, the fact that faculty appointments are clearly driven by the number of high impact-factor publications, has led some research areas to the brink of extinction. For example, everybody - from scientist to politician - is interested in studies of biodiversity, especially with respect to anthropogenic impacts and global climate change - however, the number of appointments of taxonomists to jobs at lead institutions has been negligible, despite the fact that they are instrumental to the understanding of biodiversity. Fields that do not attract a wider audience in the short term-and/or research funding (and especially institutional overheads) - are often regarded as unimportant, and so the long-term consequences for that particular area of research are neglected. The appointment of a scientist to a lead department is therefore directly dependant upon the attractiveness of the peer's science to high-ranking journals with a wide audience. In most national systems, the institution itself is assessed by exactly the same review measures, which regulate the distribution of available research funding. Major funding agencies also look out for science of broad appeal-because they examine the same measures of impact when assessing research proposals. Within this context, the meaning of 'impact' is almost synonymous with 'relevance to stakeholder communities'.

Today, a junior researcher is forced to follow the 'publish-or-perish' slogan in order to make a way into academia and indeed, targeting of high impact journals 
appears to be the primary performance measure (possibly of equal importance to funding income in an age of Full Economic Costing) to eventually enter a more permanent situation in a faculty or research department. I have often wondered whether Charles Darwin would have been able to complete his tedious work 'On the Origins of Species' that took decades of research, if as a young man he was urged to publish his monograph scattered over dozens of short journal articles? Would the final synergetic outcome of his life achievement have been the same? Of course, he did publish a lot of different works other than his very famous book, but I think asking this question remains valid, and impossible to answer at the same time.

In recent years, there have been quite a few initiatives questioning the role of the currently practiced peer review system (Riisgård 2000, 2003). Has the scientific community lost control over the (evolution of) impact measures on publishing? Has peer review become too powerful and influential on the 'free world of science'? There is a surprisingly rich body of literature available on this topic, which by its existence indicates that the issue of peer review does divide the scientific community. I am not going to reflect on this any further, but will herein summarise personal views (that are not set in stone) on the specific topic of journal peer review.

First of all, I believe that the institution of peer review in journal publishing has not failed itself. As an editor and author, I certainly subscribe to the view that the peer review does improve the quality of research manuscripts and provides a useful platform for scientific discussion. Many editors would probably agree (Riisgård 2003) that the peer review process does its job; the difficulty in objectively assessing a research manuscript lies with the peripheral effects of the publishing system, such as competitive situations and the targeting of adequate reviewers. The 'publish or perish' principle is increasingly flooding lead journals with manuscripts and the number of written scholarly works these days is unprecedented. On the other hand, reaching objective quality assessment is getting more difficult because scientists increasingly refuse to assess manuscripts (Fee 1998; Riisgård 2003). This often includes senior researchers who are supposed to be the most experienced peers in their subject area. The reason for this can likely be found in 1) the academic pressures on everyone causing time management/priority problems, 2) the sheer number of review requests senior scientists have to deal with, and 3) the limited reward for reviewers. The pressure of publishing both in quantity and quality (here referred to as publications in high impact factor journals) also causes some absurdities in author behaviour that are counterproductive to maintaining quality standards: authors that receive rejection of their manuscript following peer review increasingly do not consider any of the suggestions made by their peers but submit elsewhere without changes to the manuscript; double publication of (slightly changed) manuscripts is another phenomenon increasingly observed. This unfortunately raises the question of whether peer review is failing over the pressures of publishing as quickly and as much as possible, no matter the content. This scenario could indeed lead to a serious situation for the scientific community and affect the quality of science overall. Although different scientific schools may not agree on a subject at times, it appears that the possibility of improving one's work is not always of highest priority; this is when publishing becomes a matter of chance, a gamble if not some kind of 'lottery', and the practice of scientific publishing itself is at stake (Neff and Olden 2006).

The described scenario obviously neglects the vast amount of frontline research submitted to journals such as Naturwissenschaften, and the tremendous commitment by most members of the scientific community in their roles as authors, reviewers, and editors in practicing and promoting the very best research. However, we know that single misuse of practice can affect the reputation of an entire community, and the control of such practice is not without problem.

Editors and editorial board members mostly serve the science community to the best possible level, but the possibility that the assessment of individual academic work fails, is inevitable. Several studies have also found evidence for editorial bias in journal publishing and reviewer selection process (Pickar 2007), including a control for the prestige of the journal (Rand and Pfeiffer 2009). As far as it regards journal publishing, many quality control factors have been developed and are in place (e.g. Thatje 2009), but especially multidisciplinary journals face the problem that the wide range of research areas may not always be covered by the expertise of the editorial board. One could argue that authors target the wrong journal, and have been unable to read the scope of the journal as signalled by the representatives of the editorial board; such wrong judgement by authors is relatively common, and quick enquiries to the editor can significantly shorten manuscript assessment times.

Concluding, I advocate that peer review remains the essence of journal publishing; it assesses the quality and significance of a scholarly work and where it is published. At the same time, the place of publication will largely influence the level of dissemination of the work and the likely impact it is going to have. This selection process is for broad and immediate impact and does not declassify the value of research that is simply directed to a smaller, more specialist user community. Even journals that negate the Impact Factor system mostly rely upon peer review in quality assessment of scholarly work, and some Open Access journals are very successful, indeed. 
Journals cannot be made responsible for the unfortunate misuse of publication impact factors in science politics. It depends on the science management and political decision makers to decide what sciences are of priority to the society short and long term. In the end, what a society wishes to or can afford, will determine its long-term competitiveness.

But what about non-peer reviewed work, is it all bad? $\mathrm{PhD}$ theses and often Conference Proceedings are not assessed by impact factor, although the standard of peer review, especially in the case of $\mathrm{PhD}$ thesis work, can be very high. Sometimes journals are taken off Thomson's ISI list, which does not necessarily say anything about the quality of the published body of work in such journals. Although I do personally not see any future in non-peer reviewed literature, I advocate for considering the socalled grey literature whenever it is relevant for potentially improving one's work and in support of the advancement of science. Among the best examples are that of biodiversity and ecosystem change research where (peerreviewed) baseline data often only reach back few decades, hardly allowing for any assessment of what has been the state prior to i.e. anthropogenic impact (Thatje et al. 2007). Neglecting any such evidence available-peer reviewed or not - and in support of unravelling long-term trends, would be irresponsible.

\section{References}

Bornmann L, Daniel H-D (2010) Citation speed as a measure to predict the attention an article receives: an investigation of the validity of editorial decisions at Angewandte Chemie International Edition. J Informetr 4:83-88

Fee E (1998) A message from the editor: reviewing for L\&O. ASLO Bull 7:5

Kinne O (1988) The scientific process - its links, functions and problems. Naturwissenschaften 75:275-279

Kinne O (1999) Electronic publishing in science: changes and risks. Mar Ecol Prog Ser 180:1-5

Kronick DA (1990) Peer review in 18th-century scientific journalism. JAMA 263:1321-1329

Neff BD, Olden JD (2006) Is peer review a game of chance? Bioscience 56:333-340

Pickar JH (2007) Do journals have a publication bias? Maturitas 57:16-19

Rand DG, Pfeiffer T (2009) Systematic differences in impact across publication tracks at PNAS. PLOS One 4(1-5):e8092

Riisgård HU (2000) The peer-review system: time for re-assessment? Mar Ecol Prog Ser 192:305-313

Riisgård HU (2003) Misuse of the peer-review system: time for countermeasures? Mar Ecol Prog Ser 258:297-309

Thatje S, Laudien J, Heilmayer O, Nauen CE (2007) Understanding El Niño-The importance of Grey Literature in coastal ecosystem research and management. Mar Policy 31:85-93

Thatje S (2009) The science of nature. Naturwissenschaften 96:421422

Thompson DF, Callen EC, Nahata MC (2007) New Indices in scholarship assessment. Am J Pharm Edu 73:1-5 